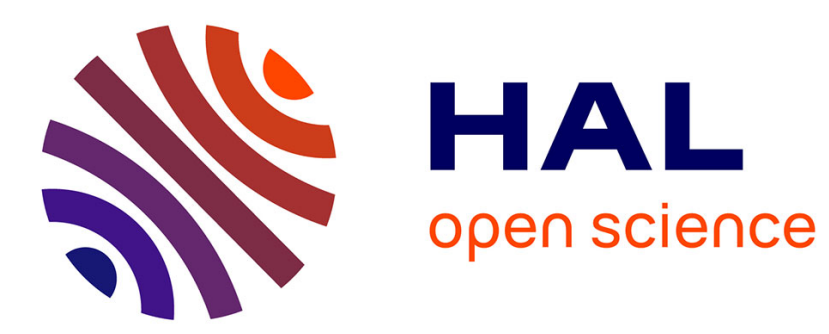

\title{
Ontogeny and morphology of the bulbus, part of the male reproductive organ in Apis mellifera carnica (Hymenoptera, Apidae)
}

Lien Moors, Gudrun Koeniger, Johan Billen

\section{- To cite this version:}

Lien Moors, Gudrun Koeniger, Johan Billen. Ontogeny and morphology of the bulbus, part of the male reproductive organ in Apis mellifera carnica (Hymenoptera, Apidae). Apidologie, 2012, 43 (2), pp.201-211. 10.1007/s13592-011-0094-9 . hal-01003634

\section{HAL Id: hal-01003634 \\ https://hal.science/hal-01003634}

Submitted on 1 Jan 2012

HAL is a multi-disciplinary open access archive for the deposit and dissemination of scientific research documents, whether they are published or not. The documents may come from teaching and research institutions in France or abroad, or from public or private research centers.
L'archive ouverte pluridisciplinaire HAL, est destinée au dépôt et à la diffusion de documents scientifiques de niveau recherche, publiés ou non, émanant des établissements d'enseignement et de recherche français ou étrangers, des laboratoires publics ou privés. 


\title{
Ontogeny and morphology of the bulbus, part of the male reproductive organ in Apis mellifera carnica (Hymenoptera, Apidae)
}

\author{
Lien Moors $^{1}$, Gudrun Koeniger ${ }^{2}$, Johan BILlen ${ }^{1}$ \\ ${ }^{1}$ Zoological Institute, University of Leuven, Naamsestraat 59, Box 2466, 3000 Leuven, Belgium \\ ${ }^{2}$ Institut für Bienenkunde (Polytechnische Gesellschaft), Fachbereich Biowissenschaften, Goethe Universität, \\ Frankfurt am Main, Karl-von-Frisch-Weg 2, 61440 Oberursel, Germany
}

Received 25 May 2011 - Revised 24 August 2011 - Accepted 7 September 2011

\begin{abstract}
The bulbus is a part of the unique functional penis (endophallus) in the genus Apis and was studied in Apis mellifera drones. The bulbus consists of a thin cuticular membrane, covered by four different epithelia (dorsal epithelium, anterior epithelium, ventral epithelium I and ventral epithelium II). One day before eclosion, pupae have no sclerotised plates in the bulbus lumen. In emerging drones, however, the lumen contains tanned plate-like structures, the chitin plates, subjacent are small droplets. The chitin plates are connected to each other by a transparent matrix. They consist of globular sclerotized structures which are connected by a network of fibrils. In young adult drones, the dorsal and lateral epithelia consist of highly columnar gland cells which decrease in thickness from the age of 6-12 days from 140 to $20 \mu \mathrm{m}$. The ultrastructural analysis combined with histochemistry shows that the gland cells secrete proteinaceous droplets towards the lumen which pass through the cuticle and the pores of the chitin plates and accumulate in the matrix. In sexually mature drones, all secretions have merged to a rigid connective substance, which extends laterally as a thin tapering membrane. The ventral epithelia I and II have no secretory function. The ventral epithelium II has a mucus-like content and several invaginations towards the lumen of the bulbus which enables widening of the bulbus orifice to discharge the bulbus secretions filled with viscous mucus via the cervix into the queen during the mating process.
\end{abstract}

morphology / ontogeny / ultrastructure / bulbus / endophallus / honeybees / drones

\section{INTRODUCTION}

In most insects, the male reproductive tract is equipped with one or more accessory glands (AG). Embryologically, these glands derive mainly from the paired mesodermal ducts descending from the testes. Some insects such as higher dipterans (Leopold 1976) or Apis (Zander 1916; Snodgrass 1956; Koeniger et al. 1996) have, in addition, glands at the ectodermal part of the reproductive tract. The secretions of male AGs

Corresponding author: J. Billen, johan.billen@bio.kuleuven.be Manuscript editor: Klaus Hartfelder represent a wide range of substances: proteins, carbohydrates, lipids and a variety of biologically active components (Gillott 1988; Colonello and Hartfelder 2005). Their functions differ accordingly, they may form spermatophores for sperm transfer or mating plugs to prevent further copulations, they may manipulate the post-copulatory behavior of females or assist the spermatozoa after transfer into the female (Wolfner 1997; Gillott 1996, 2003).

In Apis mellifera drones, three male accessory glands have been described, the mesodermal mucus gland (Snodgrass 1941; Zander 1922, Moors et al. 2005), the bulbus gland (Zander 1916; Snodgrass 1941; Woyke 1958a, 
b; Koeniger and Hänel 1996), and the cornua glands (Koeniger et al. 1996; Moors and Billen 2009). Their activity is age dependant with a core activity in adult drones during the first 5 days (mucus gland: Colonello and Hartfelder 2003; Moors et al. 2005; cornua gland: Koeniger et al. 1996; Moors and Billen 2009; bulbus gland: Koeniger and Hänel 1996). The knowledge of their compounds and their bioactivity is still fragmentary.

Secretions of these three glands are part of the mating sign left by each drone after mating in the sting chamber of the queen (Woyke 1958b; Woyke and Ruttner 1958). It does not hinder further mating of queens but is removed in less than a second by the next copulating drone (Koeniger 1986). Other functions could be shown as it also serves as an optical mark for the other drones competing in the drone aggregation areas (Koeniger 1990). Further, the secretions seem to strengthen the connection of the pair during copulation on the wings (Woyke 1958a; Gary 1969; Koeniger 1984).

The bulbus is described as a bulb-like enlarged part of the endophallus, as the membranous functional penis is called in Apis. In situ, it is connected cranially to the ejaculatory duct and distally opens into the cervix by a triangular aperture (Snodgrass 1941). As is typical for the entire endophallus, the epidermis is mostly thin and flexible consisting of a membranous cuticle covered by a monolayered epithelium. The epithelium of the bulbus was supposed to consist of two different cell types; dorsally, there are glandular cells while ventrally the cells are flat (Woyke 1958b; Koeniger and Hänel 1996). The lumen of the bulbus contains dorsally two large, elongate, posteriorly tapering plates separated by a narrow median external groove. They are hard and tanned and were named chitinous plates (Snodgrass 1941, 1956). Branching from the posterior part of each plate are small triangular lateral plates with a spiny margin (Snodgrass 1956). Beneath the dorsal and between the lateral plates, a "deep brownish thickening" material was described and interpreted as a cuticular intima (Snodgrass
1956) or as connective substance (Woyke 1958b). The chemical composition of the bulbus secretions is still unknown.

The aim of this study is to clarify the ontogeny and morphology of the bulbus and to characterize the origin and chemical nature of the chitin plates with their connective substance secreted by the epidermal gland cells.

\section{MATERIAL AND METHODS}

The bulbus gland is studied in drones of nine age categories from pupae to adults. The male pupae were obtained from a hive of $A$. mellifera carnica in Kampenhout (Belgium) and were sampled 7, 9, 11, 13 days after brood cell closure. The adults were obtained from hives in Oberursel (Germany) at the ages of $0,3,6,9,12$ days after emergence. We investigated all age-related subcategories (pupa and adult drones) of the hives in both countries and we found no substantial differences.

The bulbus was dissected and fixed in cold 2\% glutaraldehyde, buffered at $\mathrm{pH} 7.3$ with $50 \mathrm{mM} \mathrm{Na}$ cacodylate and $150 \mathrm{mM}$ sucrose. Photographs were taken with a digital camera on an Olympus BX-51 microscope. Postfixation in $2 \%$ osmium tetroxide in the same buffer was followed by dehydration in a graded acetone series (50-70-90-100\%). The structures were embedded in Araldite and sectioned with a Reichert OmU2 microtome and stained with methylene bluethionin. Semithin sections $(1 \mu \mathrm{m})$ for light microscopy were observed with an Olympus BX-51 microscope.

Ultrathin sections $(70 \mathrm{~nm})$ were made with a Reichert Ultracut E microtome and manually double stained with uranyl acetate and lead citrate. The sections were studied with a Zeiss EM900 electron microscope.

Tissues for scanning microscopy were dehydrated in a graded ethanol series (30-50-70\%). Afterwards, the samples were washed with $70 \%$ ethanol before exposure to dimethoxymethane. Samples were critical point dried using liquid $\mathrm{CO}_{2}$ with a BAL-TEC CPD030 instrument. Finally, material was coated with gold and observed in a JEOL JSM 6,360 scanning electron microscope.

For the histochemical application of different staining methods (Bancroft and Gamble 2008), the samples were embedded in LR-White resin and sectioned with a Reichert OmU2 microtome $(1 \mu \mathrm{m})$. 
Periodic acid Schiff reagent was used for the detection of sugars. The periodic acid excludes contamination, whereas Schiff's reagent makes the sugars visible with a pink staining. The proteins are detected with a Coomassie staining.

On paraffin sections $(3 \mu \mathrm{m})$, we used a trichrome (Masson) staining procedure. This staining involves the combined use of haematoxylin, Ponceau Fuchsin, and aniline blue. Nuclei and connective tissue usually stain blue, cytoplasm, muscles, and certain categories of protein red. The trichrome staining according to Masson was performed on the chitin plates and associated structures of the bulbus. The staining is known to give a red color to soluble fibrillar proteins such as fibrin, actin and myosin. The general rule in trichrome staining is that a smaller dye molecule will penetrate and stain a tissue element, but whenever a larger dye molecule can penetrate the same element, the smaller molecule will be replaced by it. We also performed a Grocott, Congo red, hemalum-eosin and periodic acid schiff (PAS) staining on paraffin sections of the bulbus to obtain more detailed data on the chemistry of the chitin plates.

Grocott targets carbohydrates in chitin and surrounding material in fungi. The polysaccharides present can be converted by oxidation (by means of, e.g., chromic acid) to dialdehydes and can thus be detected with hexamine silver solutions. Congo red stains very specifically proteins within amyloid fibrils (=proteins and sugar fractions). PAS converts the 1:2 glycol group in the hexose molecule to an aldehyde which is stainable by the Schiff reagens.

We investigated six individuals of each age category for the morphology part and four individuals for the histochemistry part of the study.

\section{RESULTS}

\subsection{Sequence of developmental steps forming the bulbus}

The bulbus is a special part of the ejaculatory duct. It is a bulb-like enlargement, unpaired, and situated in the ventral region of the drone's abdomen (Figure 1).

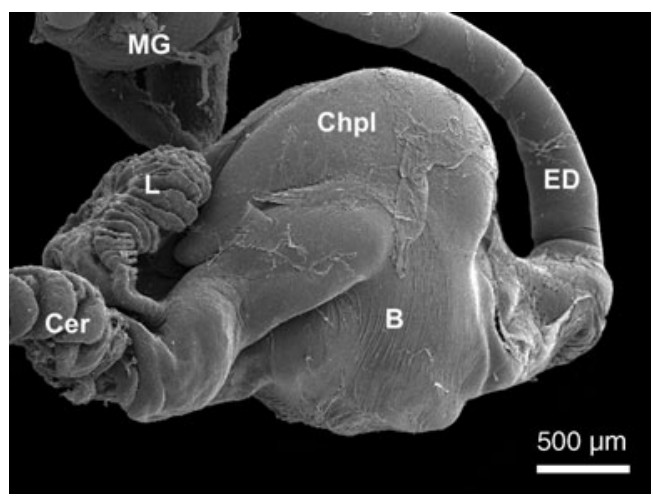

Figure 1. Scanning micrograph of the bulbus of a 3-day-old A. mellifera drone. B bulbus, Cer cervix, $C h p l$ chitin plates, $E D$ ejaculatory duct, $L$ lobe, $M G$ mucus glands.

It develops from a simple tube via a curved tube towards a complex structure: In 7-day-old pupae, the bulbus is just a simple tube with beginning evagination of the lobe at its dorsal surface. Two days later, the bulbus is more curved and the lobe becomes more straight (Figure 2a, b). The structure curves further, and the ventral surface differentiates gradually. In the last pupal stage shown, the diameter of the bulbus is nearly twice that of the first stage (Figure 2c, d). The chitin plates are not yet present in a 13-day-old pupa but fully developed in just emerged drones (Figure 2e, f). Thus, they are produced within 2 days.

\subsection{Age-dependent morphology of the epithelium in adult drones}

\subsubsection{Light microscopy}

Histological sections show that the bulbus of adult drones contains four different epithelia: a dorsal and anterior epithelium and two different ventral epithelia (further called I and II), which show considerable differences with respect to age. The epithelial cells of the anterior and dorsal epithelium of adult drones are glandular cells with a columnar appearance with high cylindrical cells. Ventral epithelium I has flat- 

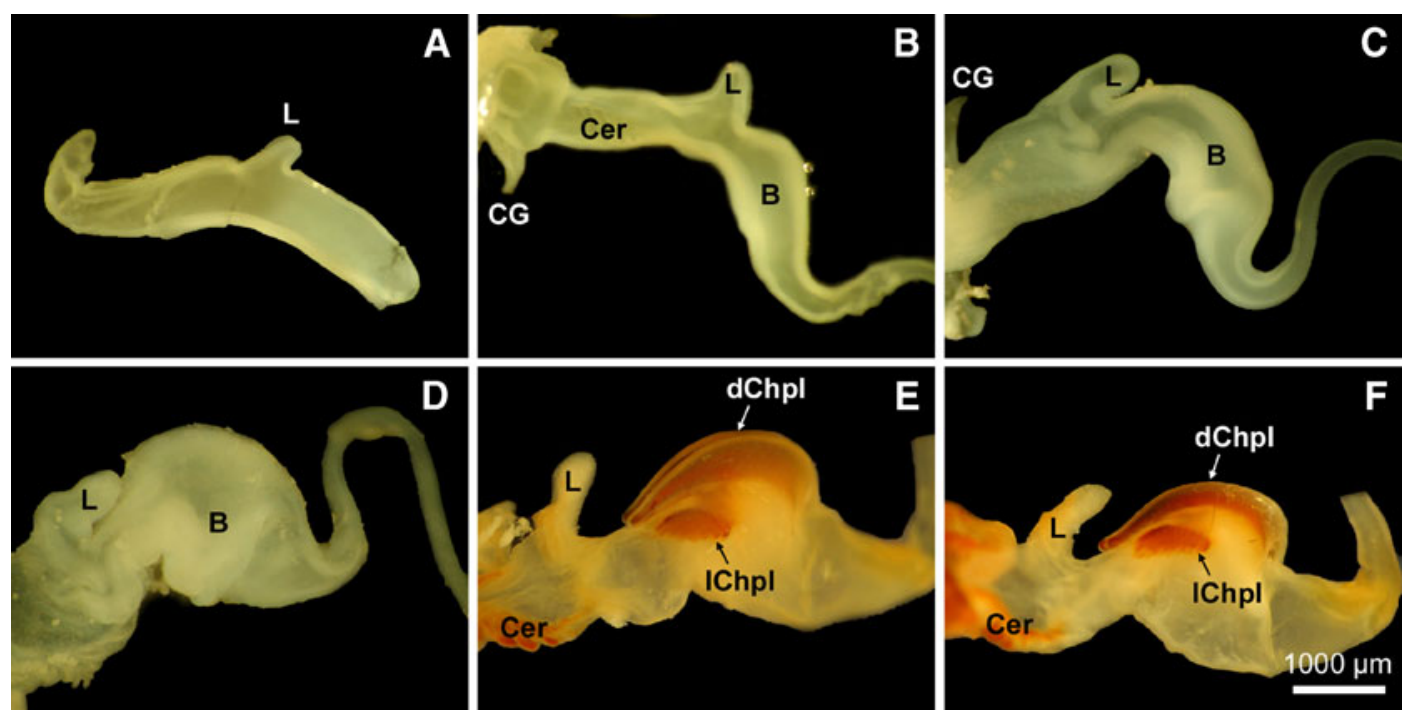

Figure 2. Dissection images of the development of the bulbus. a-d Pupae of respectively 7, 9, 11, 13 days after brood cell closure, e just-emerged drone, f sexually mature drone. $B$ bulbus, $\mathrm{Cer}$ cervix, $C G$ cornua glands, $d C h p l$ dorsal chitin plates, $L$ lobe, $l C h p l$ lateral chitin plates. Anterior side is to the right.

tened cells whereas the cells of ventral epithelium II are more irregular with a mucus-like content (Figure 3a). Only in the cuticular region attached to the anterior epithelium, secretion vesicles are visible. There is a noticeable color difference in the anterior epithelium, near the region containing secretion vesicles in the cuticle (Figure 3b).
This is confirmed for all adult age classes examined in the non-everted state.

At the onset of adult life, the thickness of the dorsal and anterior epithelium amounts already to more than $100 \mu \mathrm{m}$. It still increases and starts to decrease around day 6. Ventral epithelium I shows a slight increase but starts already to
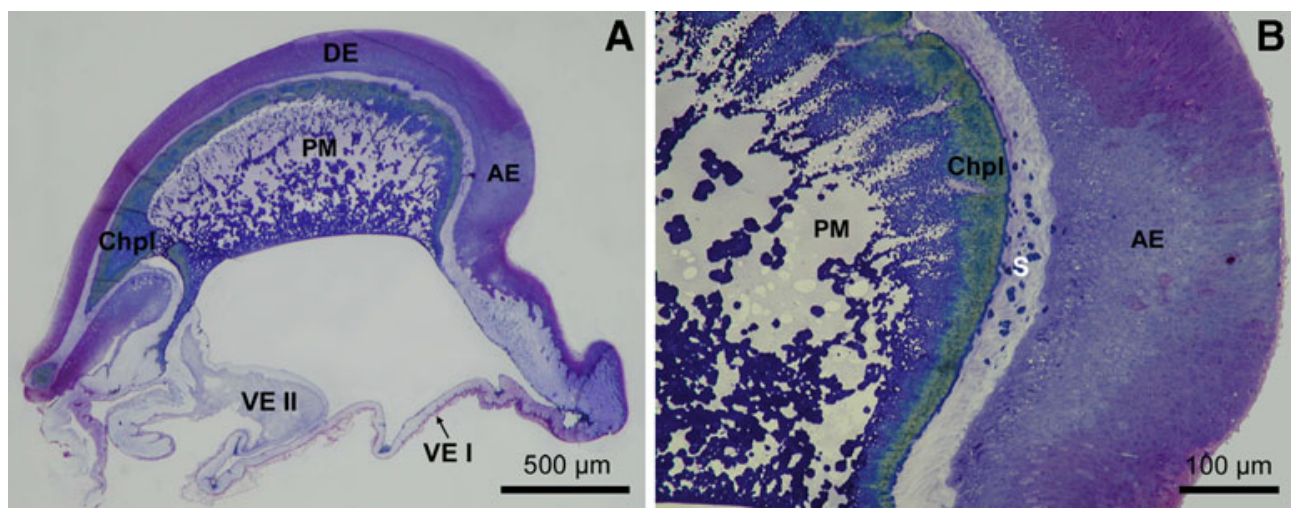

Figure 3. Light microscopy images of the bulbus gland of a 6-day-old drone. a Sagittal overview of the bulbus showing the four different epithelia, $\mathbf{b}$ anterior epithelium and detail of the secretory vesicles present in the cuticle. $A E$ anterior epithelium, $C h p l$ chitin plates, $P M$ primordial matrix, $S$ secretion, $V E I$ ventral epithelium I, $V E I I$ ventral epithelium II. Anterior side is to the right. 
decrease around day 3 (Figure 4). Ventral epithelium II could not be properly measured because this epithelium has a very irregular thickness.

\subsubsection{Electron microscopy}

The most conspicuous ultrastructural changes of the columnar cells of the dorsal and anterior bulbus region, in relation to age, are described below. For ventral epithelium I, only the age of 6 days is studied by means of EM as, according to various semi-thin sections, almost no increase of epithelial thickness was observed.

The dorsal epithelium with highly cylindrical cells In callow individuals, the Golgi apparatus and mitochondria are not abundant and tubular rough endoplasmic reticulum (RER) is present. In the neighborhood of the microvilli, large spherical lacunas are visible. No secretory vesicles are present at this age. At the age of 3 days, the Golgi apparatus (GA) is still present and mitochondria are clearly visible at the basal side which shows almost no membrane invaginations. The RER has a vesicular appearance and also smooth endoplasmic reticulum (SER) is present. As in the case of just emerged drones, large spherical lacunas are visible in the neighborhood of the microvilli. The 6-day- old stage shows a variation in the amount of vesicular SER and tubular RER is mostly present around the nuclei.

As in the two previous age categories, large spherical inclusions are visible at the apical side at the age of 9 days. The epithelium of drones of 9 and 12 days shows similarities. Lysosomal structures are present in the cytoplasm (Figure 5a). The RER is reduced to some stacks and mitochondria are elongated. The only differences between 9 and 12 days is that the Golgi apparatus in the epithelium of a 9-day-old drone is still present whereas in a mature drone there are just some GA remainders between the remnants of the cell membranes and cytoplasm.

The anterior epithelium In newly emerged drones, tubular RER is present in stacks. In contrast to the dorsal epithelium at this age, secretion is present in minimal quantities. The Golgi apparatus is clearly visible mainly in the central region of the cells. In the epithelium of 3-day-old drones, besides RER in parallel stacks situated in the central region, also vesicular SER is present. At the apical side of the anterior bulbus epithelium of drones of 6 days, the spherical secretory inclusions are electron dense and accumulated in the region of the microvilli. The production of secretion starting from less electron dense material is clearly visible. Sev-
Figure 4. Epithelial thickness of three different epithelia of the bulbus of adult drones of A. mellifera in relation to age $(n=6)$. The measurements "ventral" refer to ventral epithelium I.

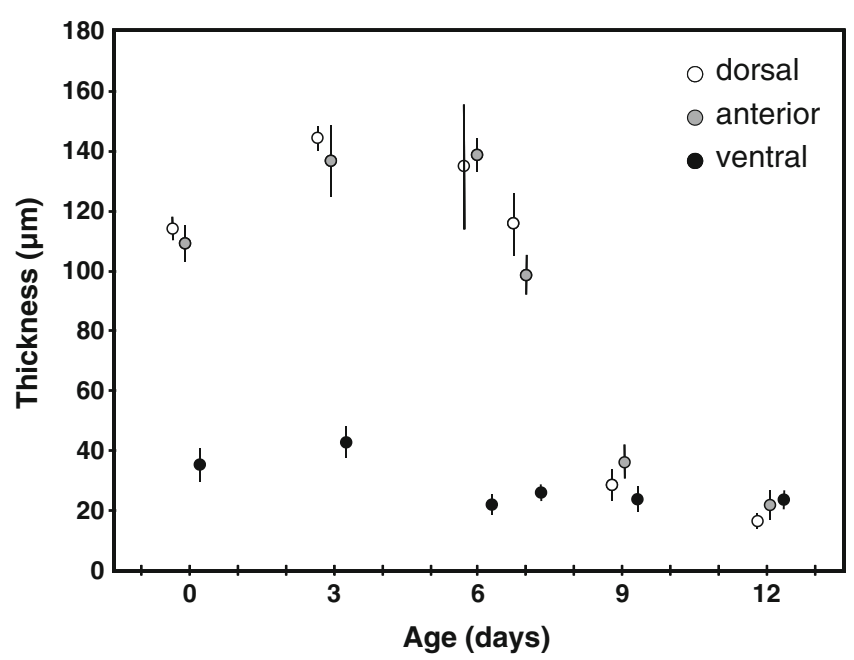



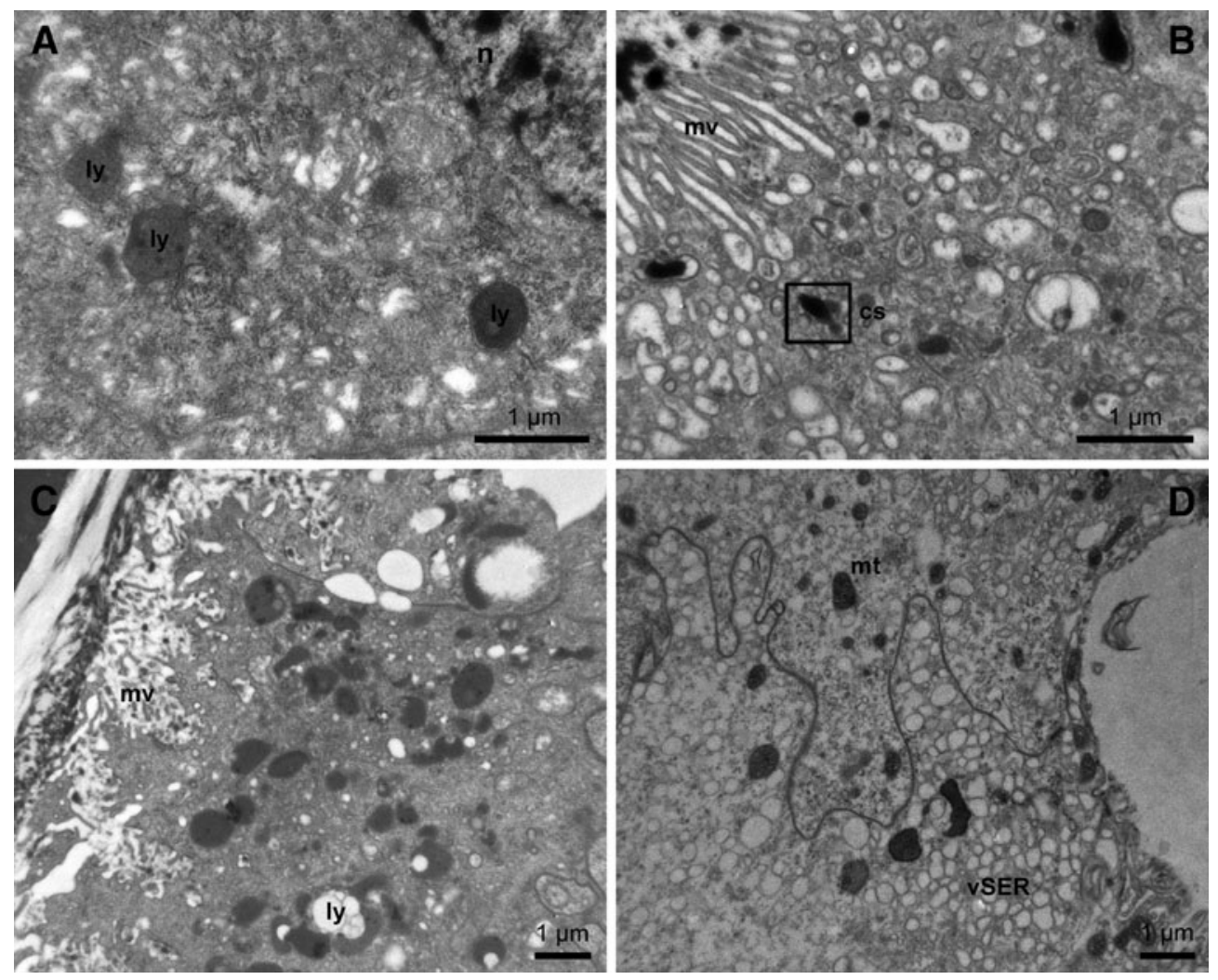

Figure 5. Electron micrographs of the epithelia of the bulbus gland. a Dorsal epithelium of a 9-day-old drone, b-c anterior epithelium of a drone of 6 and 12 days, respectively, $\mathbf{d}$ ventral epithelium I of a 6-day-old drone. $c s$ Condensing secretion, $l y$ lysosomes, $m t$ mitochondria, $m v$ microvilli, $n$ nucleus, $v S E R$ vesicular smooth endoplasmic reticulum. The framed region shows vesicles of intermediate electron density fusing into more electron-dense inclusions.

eral vesicles of intermediate electron density fuse into more electron dense inclusions (Figure 5b). The 9-day-old adult stage generally shows secretory vesicles at the apical region, the presence of tubular RER, lysosomal structures $(>1 \mu \mathrm{m})$, and spherical inclusions in the neighborhood of the microvilli. In mature drones, the cell membranes are crumpled and mainly nuclei with decondensed chromatin are visible. In the apical region, secretion vesicles are visible as well as an accumulation of lysosomes (Figure 5c).

The ventral epithelium At the age of 6 days, the ventral epithelium cells show the presence of vesicular SER and a small amount of vesicular
RER. Furthermore, not much organelles are visible at this adult stage (Figure $5 \mathrm{~d}$ ).

\subsection{Focus on the enigmatic chitin plates}

\subsubsection{Morphological overview}

Scanning electron microscopy confirms the presence of two dorsal and two lateral chitin plates within the lumen of the bulbus (Figure $6 \mathrm{a}, \mathrm{b}$ ). The outer region of the chitin plates is not layered. Contrarily, dense aggregations of globular structures are connected by a network of fibrils. Frequently, this network is interrupted by small gaps (Figure 6c, d). The 

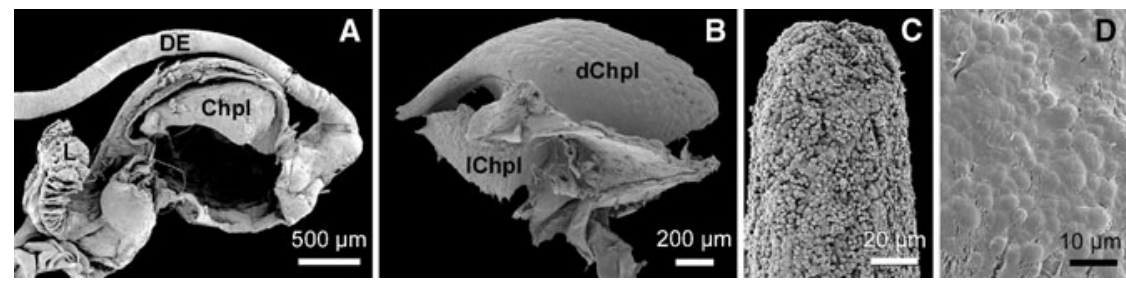

Figure 6. Scanning micrographs of the bulbus. a The entire bulbus split open to reveal the dorsal chitin plates, b the removed dorsal and lateral chitin plates, $\mathbf{c}-\mathbf{d}$ detail of the chitin. Dense aggregations of globular structures are clearly visible. $d C h p l$ Dorsal chitin plates, $D E$ ductus ejaculatorius, $C h p l$ chitin plates, $L$ lobe, $l C h p l$ lateral chitin plates.

lateral chitin plates have tiny spines. Light microscopy araldite sections of the dorsal chitin plates show numerous spherical structures making up $90-100 \%$ of the connective substance.

In the last pupal stage, the chitin plates are already formed with a transition zone underneath the sclerotized dorsal lining (Figures 9a and 10a) as well as a transparent primordial matrix with a thickness of about $500 \mu \mathrm{m}$ (Figures $7 \mathrm{a}$ and $8 \mathrm{a}$ ). In a just-emerged drone, even more of the primordial matrix without spherical droplets is observed (Figure 8b). In 6day-old drones, the highest concentration of newly secreted droplets is found in the matrix (Figures 3a, b and 8c). During sexual maturation, there is an increasing accumulation of secretion in a centrifugal direction (Figures $7 \mathrm{~b}$ and $8 \mathrm{~d}$ ). In mature drones, the secretions merge with the matrix and the transition zone and become a compact mass designated as the "connective substance" (Figure 7d).

\subsection{Histochemical aspects}

The histochemistry of the bulbus gland of $A$. mellifera revealed the presence of sugars, lipids, and proteins in the dorsal and anterior epithelium. Histochemical analyses of the connective substance showed a high staining affinity for chemicals used in protein staining (Figure 9a). Application of the trichrome (Masson) staining on paraffin-embedded material showed a bright red staining of the connective substance, whereas the cuticle of the endophallus stains pale blue. After application of the trichrome (Masson) staining, the sclerotized upper surface of
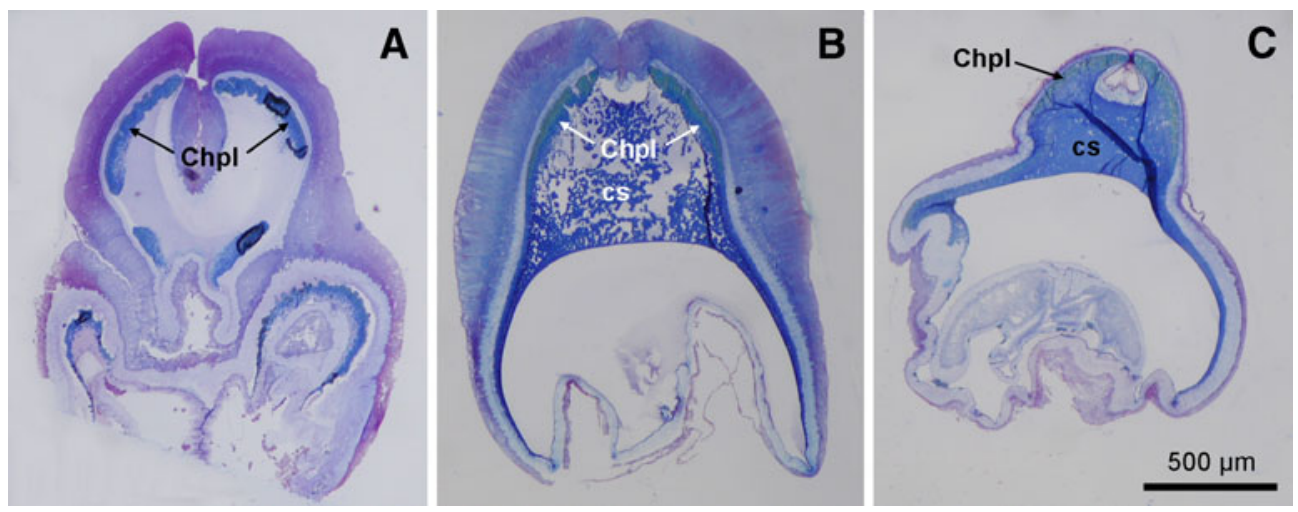

Figure 7. Light microscopy transversal images of the bulbus glands of 0,6 , and 12 days, respectively. Whereas the chitin plates are already present in emerged drones, the intensity of the connective substance increases with respect to age comparing A with C. Chpl chitin plates, cs connective substance. 

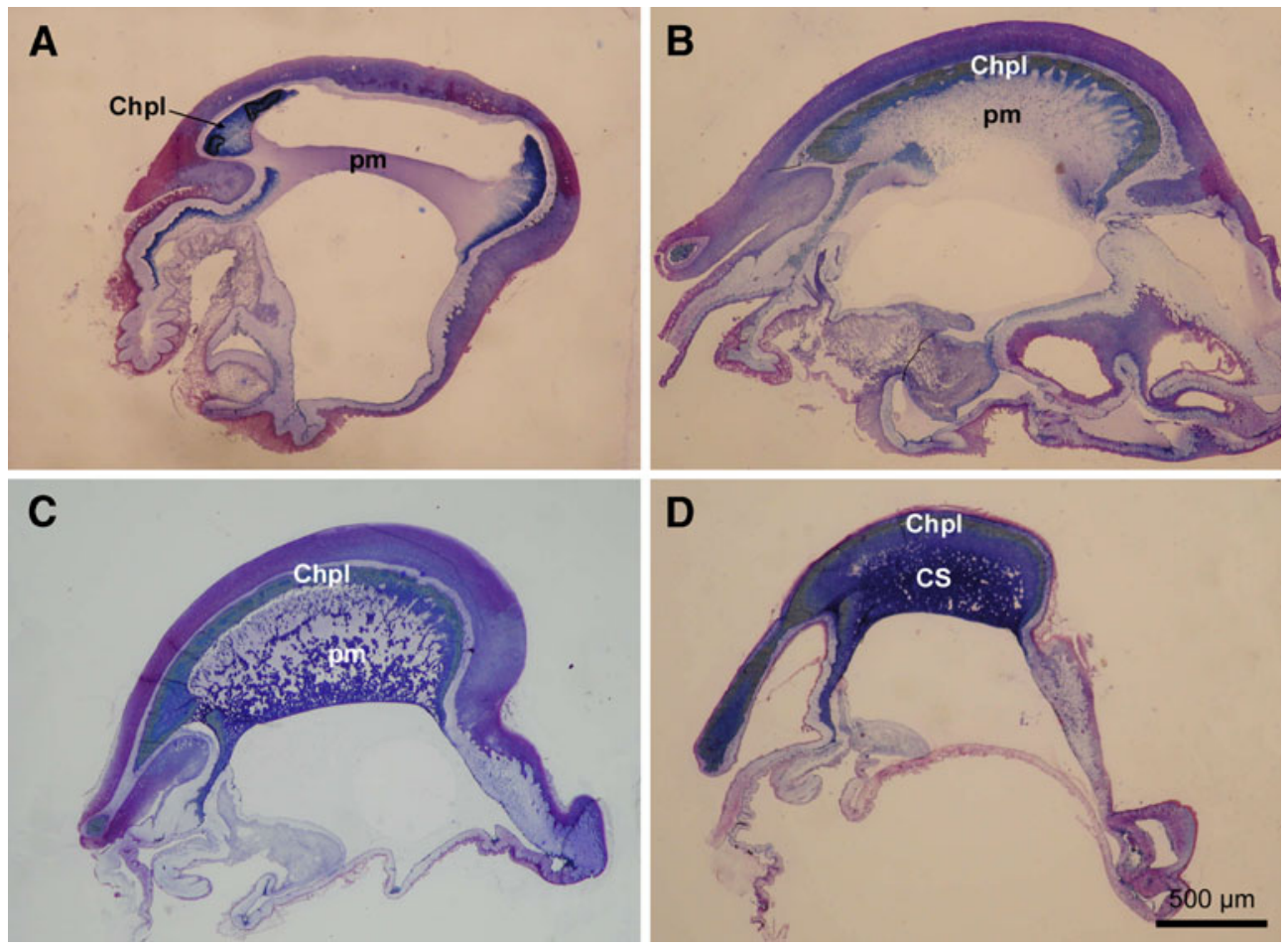

Figure 8. Sagittal sections of the bulbus gland. a Pupa of 14 days after brood cell capping, b-d drone of 0,6 , and 12 days, respectively. Note the chitin plates are already present in the last pupal day, whereas the connective substance is formed during sexual maturation. Chpl chitin plates, cs connective substance, $\mathrm{pm}$ primordial matrix.
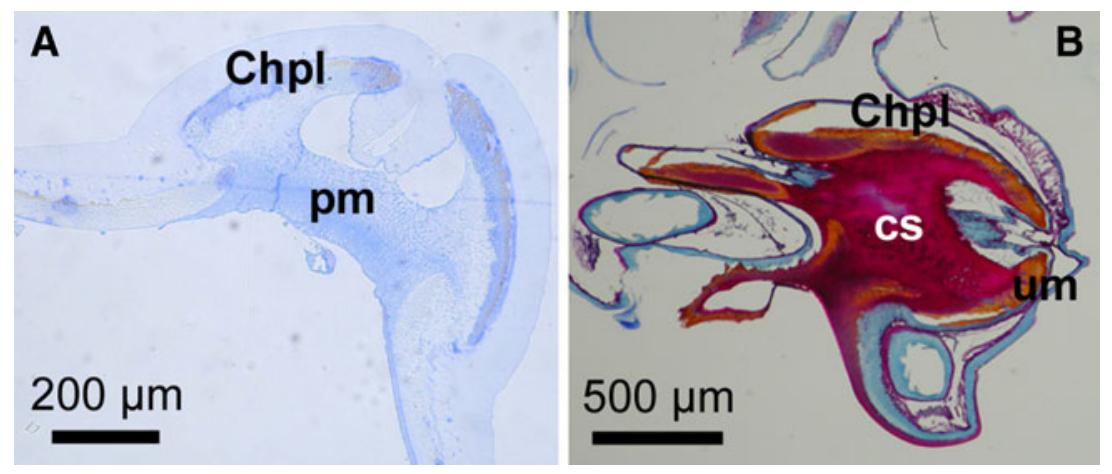

Figure 9. Histochemical images of the bulbus gland of a 9-day-old pupa. a Histochemical image of the bulbus gland stained with Coomassie blue for proteins. The connective substance is stained blue which indicates the presence of proteins. b Image of trichrome (Masson) staining of an everted endophallus (nuclei and connective tissue blue; cytoplasm, muscles, and certain categories of protein red). Chpl chitin plates, cs connective substance, $\mathrm{pm}$ primordial matrix, um unstained (outer) margin of the chitin plates. 
the chitin plates, sectioned with a thickness of $3 \mu \mathrm{m}$, results in a yellowish appearance (Figure 9b). Application of the different histochemical techniques is summarized in Figure 10.

\section{DISCUSSION}

\subsection{The bulbus and its epidermis}

Originating from an invagination of the ectoderm, the bulbus epidermis consists of a monolayered epithelium lined with a membranous cuticle. The differentiation of the dorsal and anterior epithelial wall into special gland cells must already occur in the pupal phase since the thickness of the epithelium of a newly emerged drone amounts to more than $100 \mu \mathrm{m}$, which is about fivefold that of inactive cells (Figure 8a). We suggest that the bulbus epithelium probably starts secreting 2 or 3 days before emergence as soon as the bulbus is differentiated into its final structure.

The epidermis proves to be more complex than previously described (Snodgrass 1956; Woyke 1958b; Koeniger and Hänel 1996). In young adult drones, the bulbus epithelium differentiates not into two but into four types of epidermal cells: The dorsal and the anterior epidermal complex consist of high columnar gland cells secreting towards the lumen while the cells of the ventral complex I and II are flattened, and no glandular activity could be detected. The ventral epithelium II with its invaginations and mucus-like contents enables the extension of the bulbus opening to allow the chitin plates and together with connective substance enclosing the viscous mucus to enter the cervix. The cervix, too, is then extended by opening a kind of hairy hook and loop fastener (Woyke 2008).

In any case, there is a temporal sequence in the secretory activity of the gland cells. In the pupal phase, the globules which sclerotize fast, the transition zone and the matrix are secreted. Only in the imago, a different type of droplets is secreted which accumulate and finally merge in the primordial matrix. Actually, no data were published yet which demonstrate this temporal sequence of different composition of the gland secretions in the pupal phase.

We also found the age-dependent activity of the dorsal as well as the anterior gland cells in
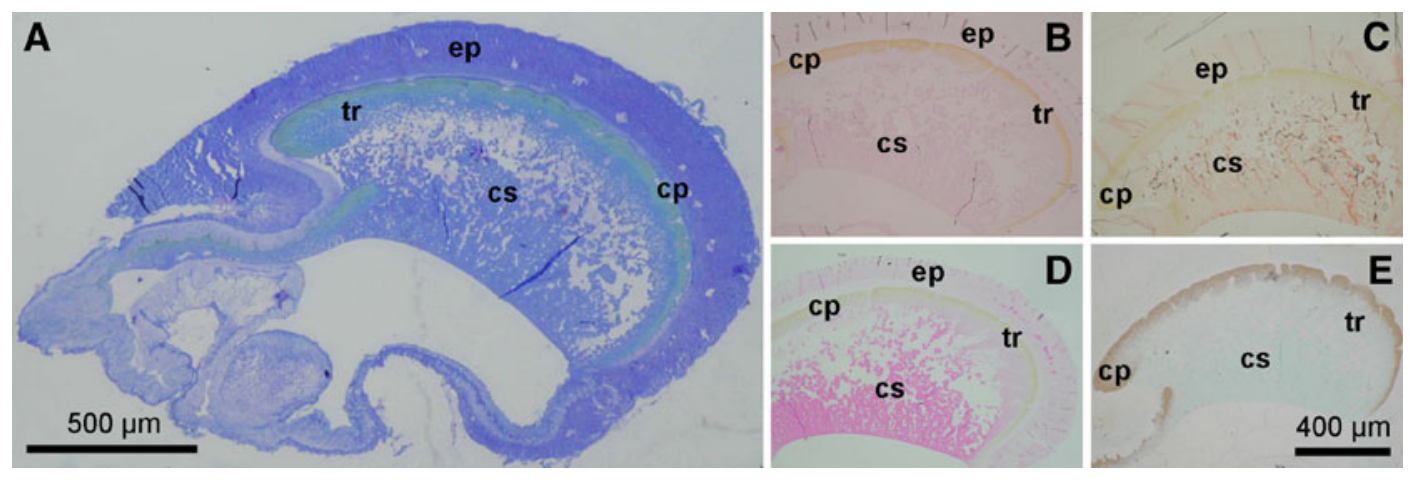

Figure 10. Histochemical staining of the bulbus. a Reference staining with methylene blue and thionin, b PAS staining for sugars, $\mathbf{c}$ Congo red staining for proteins with amyloid fribrils, d HE staining for nuclear and cytoplasmic staining, e Grocott staining for carbohydrates. In general, these techniques all show clearly different staining properties for the $c t$ layer and the $c s$ region, indicating obviously different chemical compositions; $\mathrm{cp}$ is chitinized plates, whereas cs is largely proteinaceous in combination with a carbohydrate fraction. ep Epithelium, $c s$ connective substance, $c t$ cuticle of chitin plates, $t r$ transition region; $\mathbf{b}-\mathbf{e}$ are at same magnification. 
adult drones as described before by Koeniger and Hänel (1996). We could pinpoint the start of reduction of the epithelium to drones aged 6 days. From the age of 6-12 days, the thickness is gradually reduced from about 140-20 $\mu \mathrm{m}$.

\subsection{Structure of the bulbus secretion}

From our ontogenetic study, it becomes clear that the final shape of the cuticular plates is the result of the unique structure of the bulbus itself. The shape of the bulbus is the result of a series of invaginations, resulting in some kind of telescopic structure. The anterior, posterior, and lateral folds contribute to the formation of two chitin plates, which are dorsally separated, together with two lateral plates.

The formation of the gland secretions is complex. Underneath the sclerotized tanned layers, the transition zone is stretched, which consist of small droplets and is stained well with protein sensitive dye but the color is different to the droplets secreted in adult drones. Dorsally, the sclerotized layers are separated by an untanned connective material. Ventrally of the transition zone, there is a matrix with a thickness of about $500 \mu \mathrm{m}$ into which from the first day after the drone's emergence droplets of the gland epithelium are secreted. In sexually mature drones, the transition zone, matrix, and those droplets produced after emergence have merged to a uniform mass, the connective substance. The connective substance stretches along the lateral wall and in some parts merges ventrally to a tube (Woyke and Ruttner 1958).

The sclerotized layer appears later than the cuticle and does not consist of parallel layers but is formed by dense aggregations of globular structures connected by a network of fibrils. Its surface area is porous and uneven. Accordingly, this framework is very fragile (Koeniger and Hänel 1996). Already in young drones, its rigidity is achieved by a transition zone and a primordial matrix, later the firmness is further supported by incorporation of additional secre- tions of the gland cells. As mentioned in Section 1, the sclerotized layer is described as chitin plates connected by a transparent "cuticular intima" (Snodgrass 1956). The term cuticular intima suggests a cuticular origin of this structure which is not in accordance with our results. Masson staining of our sections revealed that the connective substance contains a high percentage of proteins (bright red) while the cuticular membrane appears pale blue. Actually, all staining methods showed clear differences between the cuticular membrane of the bulbus and the connective substance. There is no proof yet if any chitin is mixed with the predominant proteinaceous components in these plates. Nevertheless, we will stick to the nomenclature "chitin plates" for the sclerotized layers of the bulbus secretions since in all former publications and textbooks (Winston 1987), this term is used.

The stepwise formation of the chitin plates with the connective substance as described above and their globular structure is remarkable. According to these results, it seems questionable that they may be homologous to transformed sclerites though the paired appearance may support such an interpretation (Snodgrass 1941). In addition, A. mellifera is the only species having sclerotized tanned layers though all cavity nesting species transfer mating signs during the mating process (Koeniger et al. 1991; Patinawin and Wongsiri 1993).

The honeybee queen mates up to 15 times during a single mating flight (Woyke 1956). Thus, it is necessary for the subsequent drones to remove the mating sign without leaving any remainders. We hypothesize that the function of the bulbus' secretions is to enclose the viscous mucus in a way and thus guarantees a sufficiently rigid but nevertheless flexible mating sign that can be efficiently removed as a whole by each subsequent drone.

Ontogénie et morphologie du bulbe, partie de l'organe reproducteur mâle chez Apis mellifera carnica (Hymenoptera, Apidae)

morphologie / ontogénie / ultrastructure / bulbe / endophallus / abeille / mâle 
Entwicklung und Morphologie des Bulbus, eines Teils des männlichen Reproduktionstrakts von Apis mellifera carnica (Hymenoptera, Apidae)

Morphologie / Entwicklung / Ultrastruktur / Bulbus / Endophallus / Honigbiene / Drohn

\section{REFERENCES}

Bancroft, J.D., Gamble, M. (2008) Theory and practice of histological techniques, 6th edn. Churchill Livingstone, Philadelphia

Colonello, N.A., Hartfelder, K. (2003) Protein content and pattern during mucus gland maturation and its ecdysteroid control in honeybee drones. Apidologie 34, $1-10$

Colonello, N.A., Hartfelder, K. (2005) She's my girlmale accessory gland products and their function in the reproductive biology of social bees. Apidologie 36, 231-244

Gary N.E. (1969) Mating behaviour of the honeybee. Proc. XXII Int. Beekeep. Congr., 413-414

Gillott, C. (1988) Arthropoda-Insecta. In: Adiyodi, K. G., Adiyodi, R.G. (eds.) Reproductive biology of invertebrates, vol. 3, pp. 319-471. Wiley, Chichester

Gillott, C. (1996) Male insect accessory glands: functions and control of secretory activity. Invertebr. Repr. Dev. 30, 199-205

Gillott, C. (2003) Male accessory gland secretions: modulators of female reproductive physiology and behavior. Annu. Rev. Entomol. 48, 163-184

Koeniger, G. (1984) Funktionsmorphologische Befunde bei der Kopulation der Honigbiene (Apis mellifera L.). Apidologie 15, 189-204

Koeniger, G. (1986) Mating sign and multiple mating in the honeybee. Bee World 67, 141-150

Koeniger, G. (1990) The role of the mating sign in honeybees Apis mellifera L.: does it hinder or promote multiple mating? Anim. Behav. 39, 444449

Koeniger, G., Hänel, H. (1996) The bulbus gland of drones (Apis mellifera L.). Pszcz. Zesz. Nauk. 2, 4554

Koeniger, G., Hänel, H., Wissel, M., Herth, W. (1996) Cornual gland in the honeybee drone (Apis mellifera L.): structure and secretion. Apidologie 27, 145-156
Koeniger, G., Koeniger, N., Mardan, M., Otis, G., Wongsiri, S. (1991) Comparative anatomy of male genital organs in the genus Apis. Apidologie 22, 539-552

Leopold, R.A. (1976) The role of male accessory glands in insect reproduction. Annu. Rev. Entomol. 21, 199-221

Moors, L., Billen, J. (2009) Age-dependent morphology and ultrastructure of the cornua glands in drones of Apis mellifera. Apidologie 40, 600-607

Moors, L., Spaas, O., Koeniger, G., Billen, J. (2005) Morphological and ultrastructural changes in the mucus glands of Apis mellifera drones during pupal development and sexual maturation. Apidologie 36, 245-254

Patinawin, S., Wongsiri, S. (1993) Male genitalia of honeybees in Asian apiculture. Proc. 1st Int. Conf. Asian Honeybees and Bee Mites, Bangkok, Thailand. Wicwas Press, Cherhire, CT, USA, pp. 110116

Snodgrass, R.E. (1941) The male genitalia of Hymenoptera. Smithsonian Institution, Washington

Snodgrass, R.E. (1956) Anatomy of the honey bee. Comstock Publ. Assoc. Cornell. Univ. Press, Ithaca

Winston, M.L. (1987) The biology of the honey bee. Harvard University Press, Cambridge

Wolfner, M.F. (1997) Tokens of love: functions and regulation of Drosophila melanogaster male accessory gland products. Insect Biochem. Mol. Biol. 27, 179-192

Woyke, J. (1956) Anatomo-physiological changes in queen-bees returning from mating flights and the process of multiple mating. Bull. Acad. Polon. Sci. 4, $81-87$

Woyke, J. (1958a) The process of mating in the honeybee. Pszcz. Zesz. Nauk. 2, 1-42

Woyke, J. (1958b) The histological structure of the reproductive organs of the drone. Publ. Sect. Agr. Sylv. 19, 38-50

Woyke, J., Ruttner, F. (1958) An anatomical study of the mating process in the honeybee. Bee World 39, 3-18

Woyke, J. (2008) Why the eversion of the endophallus of honey bee drone stops at the partly everted stage and significance of this. Apidologie 39, 627-636

Zander, E. (1916) Die postembryonale Entwicklung des Geschlechtsapparates der Drohne (Apis mellifica L.). Z. Angew. Ent. 3, 7-20

Zander, E. (1922) Der Bau der Biene. E. Ulmer, Stuttgart 